\title{
Polarized drinking patterns and alcohol deregulation
}

\section{Trends in alcohol consumption, harms and policy: United Kingdom 1990-2010}

\section{Introduction}

The aim of this paper is to explore key trends concerning the UK's relationship with alcohol over two decades (1990-2010), and to discuss the context and possible determinants of these trends. This paper cannot begin to provide a comprehensive picture. Rather, the focus will be on England as the most populous region, with comments on salient developments in the other regions where these are different. The task of comparing UK regions is complicated by England, Scotland, Wales and Northern Ireland each producing their

\section{Acknowledgements}

The author would like to thank a number of UK policy makers for informal discussions, and Norman Giesbrecht, Robin Pursehouse and Ben Baumberg for valuable comments on draft manuscripts. All views expressed are solely those of the author.

\section{Declaration of interest}

The author's salary is paid by the University of Sheffield and no separate funding was obtained for the preparation of this manuscript.

submitted 28.05.2010

initial review completed 01.10. 2010

final version accepted 04.10.2010

\section{ABSTRACT}

P.S. Meier: Polarized drinking patterns and alcohol deregulation. Trends in alcohol consumption, harms and policy: United Kingdom 1990-2010

This paper sets out to chart key trends in alcohol consumption and harm, and of related policy activity in the UK between 1990 and 2010. As a journal paper cannot provide a comprehensive picture. the focus will be on England as the most populous region, with comments on salient developments in the other regions where these are different. The paper draws on a variety of data sources, especially general population surveys, government reports, industry figures, National Statistics products, and recent reviews of data trends. It is structured around the themes: 1) trends in volume and patterns of consumption in adults and children; 2 ) trends in major alcohol-related harms; 3 ) changes in the affordability and availability of alcohol; 4) influences of major players including policy makers, media and industry and 5) the current (mid-2010) status of policy efforts. The reviewed data show that the UK has seen significant changes in the patterns and contexts of consumption during the 1990s and 2000s. Major consumption changes include falling per capita consumption, a rise in heavy episodic drinking, increasing preference of higher alcohol content beverages and a polarisation of the distribution of consumption in the population where heavy drinkers consume even higher 
volumes whilst moderate drinkers appearing to decrease their average intake. Context changes include rising availability and affordability of alcohol, with few alcohol control policy efforts, and a switch from predominantly on-trade to off-trade drinking. Such trends help explain the current rapid increase in alcohol-related admissions and other heavy end consequences in the context of falling per capita consumption.

\section{GEYWORDS}

alcohol consumption,

alcohol-related harm, policy, UK own statistics and surveys, which often have incompatible sampling strategies and consumption and harm definitions. The paper draws on a variety of data sources, especially general population surveys, government reports, industry figures, National Statistics products, and a recent review of data trends (Smith \& Foxcroft 2009). Interpretations are based on the author's observations, background reading and discussions with researchers and policy makers over the past few years. The paper is structured around the following themes: trends in volume and patterns of consumption in adults and children; trends in some of the major alcoholrelated harms; changes in the affordability and availability of alcohol; influences of major players including policy makers, media and industry and the current (mid-2010) status of policy efforts.

\section{Trends and patterns in alcohol consumption \\ - Trends in lifetime drinking and adult per capita drinking volume}

According to survey data, the balance between adult drinkers versus abstainers has remained stable for the past two decades, with about $55-60 \%$ of women and $70-75 \%$ of men drinking at least weekly, and $10-15 \%$ of both men and women not drinking at all in the past year (National Statistics 2003a; 2004a; 2005a; 2006a; 2007a; 2008a; 2009a; 2010a). Between 2004 and 2009, past-week drinking in women under the age of 25 declined. Whilst abstention rates saw no change, drinkers showed a strong increase in consumption until 2003/4 (for an overview of adult consumption trends see Table 1). When considering trends, it is important to bear in mind the limitations of survey data. Survey data underestimates true alcohol consumption (covering about $60 \%$ of alcohol clearances in 2006), and it has been suggested that decreasing response rates may mean that coverage could have decreased over time, making any observed trends less reliable.

UK customs clearance data shows that the average per capita volume consumed rose throughout the late 1990s and the first half of the 2000s and peaked at 11.8 litres in 2003/4 (HMRC 2010, see Fig 1). Since then, per capita consumption has stabilized and decreased, falling to 10.7 litres in 2008/9, just 7\% higher than in 1990 . 
Table 1. Adult consumption trends

\begin{tabular}{|c|c|c|c|c|}
\hline Construct & Age & Trend & Narrative trend & Data source \\
\hline $\begin{array}{l}\text { Volume of consumption } \\
\text { Men }\end{array}$ & & & & NS Alcohol \\
\hline $\begin{array}{l}\text { Average units per week } \\
\text { Drinking over daily limit (>4 units) } \\
\text { Drinking over binge limit } \\
\text { (>8 units per day) } \\
\text { Drinking over weekly limits (>21 units) } \\
\text { Drinking over harmful limit } \\
\text { (>50 units per week) }\end{array}$ & $16-24$ & 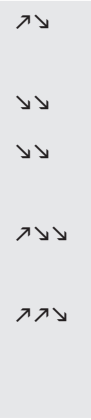 & $\begin{array}{l}\text { Marked increase to } 2000 \text {, } \\
\text { then decrease } \\
\text { Marked decrease } \\
\text { Marked decrease } \\
\text { Increase to 2000, then } \\
\text { marked decrease } \\
\text { Very marked increase to } \\
2001 \text {, then very marked } \\
\text { decrease }\end{array}$ & \\
\hline $\begin{array}{l}\text { Average units per week } \\
\text { Drinking over daily limit (>4 units) } \\
\text { Drinking over binge limit } \\
\text { (>8 units per day) } \\
\text { Drinking over weekly limits (>21 units) } \\
\text { Drinking over harmful limit } \\
\text { (>50 units per week) }\end{array}$ & $25-44$ & $\begin{array}{l}\rightarrow \\
\rightarrow ? \\
\rightarrow \searrow \\
\searrow\end{array}$ & $\begin{array}{l}\text { Stable } \\
\text { Slight decrease } \\
\text { Probably stable } \\
\text { Relatively stable to 2001, then } \\
\text { decrease } \\
\text { Decreased to } 1998 \text {, followed } \\
\text { by increase to } 2000 \text {, then } \\
\text { decrease }\end{array}$ & \\
\hline $\begin{array}{l}\text { Average units per week } \\
\text { Drinking over daily limit (>4 units) } \\
\text { Drinking over binge limit } \\
\text { (>8 units per day) } \\
\text { Drinking over weekly limits ( }>21 \text { units) } \\
\text { Drinking over harmful limit } \\
\text { (>50 units per week) }\end{array}$ & $45-64$ & $\begin{array}{l}\rightarrow \\
\rightarrow ? \\
\text { T? } \\
\rightarrow\end{array}$ & $\begin{array}{l}\text { Stable } \\
\text { Probably stable } \\
\text { Probably slight increase } \\
\text { Increase to } 1998 \text {, then } \\
\text { decrease } \\
\text { Stable }\end{array}$ & \\
\hline $\begin{array}{l}\text { Average units per week } \\
\text { Drinking over daily limit (>4 units) }\end{array}$ & $65+$ & $\pi$ & $\begin{array}{l}\text { Slight increase } \\
\text { Slight increase }\end{array}$ & \\
\hline $\begin{array}{l}\text { Drinking over binge limit } \\
\text { (>8 units per day) }\end{array}$ & & $\lambda ?$ & Probably slight increase & \\
\hline $\begin{array}{l}\text { Drinking over weekly limits (>21 units) } \\
\text { Drinking over harmful limit (>50 units } \\
\text { per week) }\end{array}$ & & $\rightarrow$ & $\begin{array}{l}\text { Increase to 1996, then } \\
\text { decrease } \\
\text { Stable }\end{array}$ & \\
\hline
\end{tabular}

Note. $\rightarrow$ Stable $\searrow$ Decrease $\pi$ Increase $\boldsymbol{x}$ Marked increase $\downarrow \searrow$ Marked decrease

${ }^{1}$ Data Sources: NS Alcohol (National Statistics 2003a, 2004a, 2005a, 2006a, 2007a, 2008a, 2009a, 2010a). Average weekly consumption data since 1992, average daily consumption and binge drinking data since 1998. Refers to past week drinking. Change in recording 2006, which affects wine drinking most.

HMRC (2010). Alcohol Fact Sheets reporting UK data since 1990.

DEFRA (2010). Family Food Datasets provide information on adult purchasing behaviours since 1997. 
Polarized drinking patterns and alcohol deregulation

(United Kingdom)

\begin{tabular}{|c|c|c|c|c|}
\hline Construct & Age & Trend & Narrative trend & Data source \\
\hline Women & & & & NS Alcohol \\
\hline $\begin{array}{l}\text { Average units per week } \\
\text { Drinking over daily limit (>3 units) } \\
\text { Drinking over binge limit ( }>6 \text { units per day) } \\
\text { Drinking over weekly limits ( }>14 \text { units) } \\
\text { Drinking over harmful limit } \\
\text { (>35 units per week) }\end{array}$ & $16-24$ & 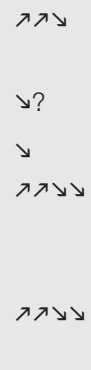 & $\begin{array}{l}\text { Marked increase to } 2005, \\
\text { then decrease } \\
\text { Probable decrease } \\
\text { Moderate decrease } \\
\text { Very marked increase to } \\
2000 \text {, stability till } 2002 \text {, then } \\
\text { marked decrease } \\
\text { Very marked increase to } \\
2000 \text {, then marked decrease }\end{array}$ & \\
\hline $\begin{array}{l}\text { Average units per week } \\
\text { Drinking over daily limit (>3 units) } \\
\text { Drinking over binge limit } \\
\text { (>6 units per day) } \\
\text { Drinking over weekly limits (>14 units) } \\
\text { Drinking over harmful limit ( }>35 \text { units } \\
\text { per week) }\end{array}$ & $25-44$ & 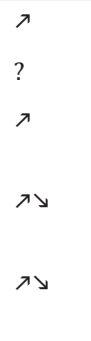 & $\begin{array}{l}\text { Increase } \\
\text { Unclear } \\
\text { Probable increase } \\
\text { Increase to 2002, then proba- } \\
\text { bly decrease } \\
\text { Slight increase to 2000, then } \\
\text { probably slight decrease }\end{array}$ & \\
\hline $\begin{array}{l}\text { Average units per week } \\
\text { Drinking over daily limit (>3 units) } \\
\text { Drinking over binge limit } \\
\text { (>6 units per day) } \\
\text { Drinking over weekly limits (>14 units) } \\
\text { Drinking over harmful limit } \\
\text { (>35 units per week) }\end{array}$ & $45-64$ & $\begin{array}{l}\lambda \\
\rightarrow ? \\
\nearrow \\
\rightarrow\end{array}$ & $\begin{array}{l}\text { Increase } \\
\text { Probably stable } \\
\text { Probably increase } \\
\text { Increase to 1998, then slow } \\
\text { decrease } \\
\text { Stable }\end{array}$ & \\
\hline $\begin{array}{l}\text { Average units per week } \\
\text { Drinking over daily limit (>3 units) } \\
\text { Drinking over binge limit } \\
\text { (>6 units per day) } \\
\text { Drinking over weekly limits (>14 units) } \\
\text { Drinking over harmful limit } \\
\text { (>35 units per week) }\end{array}$ & $65+$ & $\begin{array}{l}\rightarrow \\
\rightarrow ? \\
\rightarrow ? \\
\rightarrow \\
\rightarrow\end{array}$ & $\begin{array}{l}\text { Increase } \\
\text { Probably stable } \\
\text { Probably stable } \\
\text { Stable } \\
\text { Stable }\end{array}$ & \\
\hline \multicolumn{5}{|l|}{$\begin{array}{l}\text { Consumption patterns } \\
\text { (Men and Women) }\end{array}$} \\
\hline $\begin{array}{l}\text { Average per capita volume (ages 16+) } \\
\text { - total }\end{array}$ & & עיד & $\begin{array}{l}\text { Increase to } 2004 \text {, recently } \\
\text { stable or decrease }\end{array}$ & HMRC \\
\hline $\begin{array}{l}\text { Average per capita volume (ages 16+) } \\
\text { - beer }\end{array}$ & & $\Delta$ & Marked decrease & \\
\hline $\begin{array}{l}\text { Average per capita volume (ages 16+) } \\
\text { - wine }\end{array}$ & & ス & Marked increase & \\
\hline $\begin{array}{l}\text { Average per capita volume (ages 16+) } \\
\text { - spirits }\end{array}$ & & $\rightarrow$ & Stable & \\
\hline $\begin{array}{l}\text { Average per capita volume (ages 16+) } \\
\text { - cider }\end{array}$ & & $\pi$ & Increase & \\
\hline Off-trade \% of beer sales & & $\lambda$ & Increase & DEFRA \\
\hline Off-trade volume beer sales & & עיד & $\begin{array}{l}\text { Increase to } 2006 \text {, modest } \\
\text { decrease since }\end{array}$ & DEFRA \\
\hline
\end{tabular}


Survey results from England show that in $2006,45 \%$ of alcohol was consumed by the heaviest $10 \%$ of drinkers, $66 \%$ by the heaviest $20 \%$ and $79 \%$ by the heaviest $30 \%$. At the other end of the spectrum, the lightest $40 \%$ of drinkers accounted for only $2 \%$ of consumption (Meier et al. 2010).

Surveys make \% abv (alcohol-by-volume) assumptions when coding the unit content of beverage types (a UK unit corresponds to $8 \mathrm{gms} / 10 \mathrm{ml}$ of pure alcohol). For all government surveys, these assumptions were adjusted in 2006/2007 to correct for increasing beverage strength and serving sizes, and thus increasing underestimation of true consumption in the preceding years. Wine is more affected than other types of drinks, and thus there is some uncertainty about survey-based trends for female and older drinkers.

Average weekly consumption trends among different population groups vary substantially (National Statistics 2003a; 2004a; 2005a; 2006a; 2007a; 2008a; 2009a; 2010a). Women of all ages have been increasing their consumption steadily, or in the case of young women, very rapidly. This increase still continues in the over25 s, but young women have recently started to decrease their drinking. By 2008, the average amount consumed by women of all ages (except 65+) was very similar. In contrast, drinking levels in men have been fairly stable, with only young men $<25$ showing a marked increase in drinking during the 1990s followed by a decrease during the 2000s.

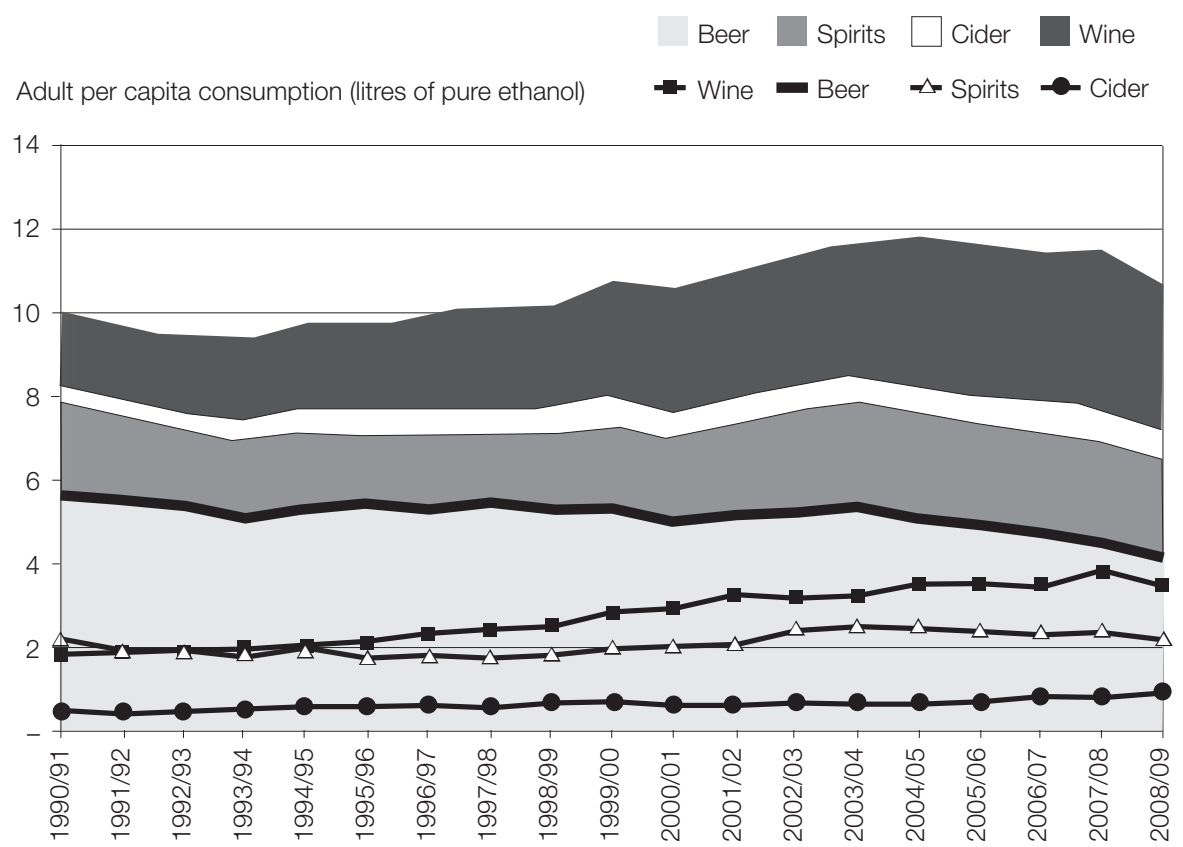

Figure 1. Beverage volumes cleared for sales by customs between 1990/1 and 2008/9, by bewerage type (lines) and cumulative (shaded areas) (https://www.uktradeinfo.com/index. cfm?task=factalcohol\&hasFlashPlayer=true). 


\section{Shifting drinking preferences}

Traditionally a beer drinking country, the UK's preference is gradually changing in favour of wine (see Figure 1 and Table 1). Between 1990 and 2008, beer clearances decreased to account for $39 \%$ of alcohol cleared for sale, wine clearances rose by $80 \%$ to account for $32 \%$, spirit clearances decreased by $10 \%$ to represent $21 \%$ of the market, and cider clearances doubled to account for the remaining $8 \%$. Note that these figures do not take into account cross-border purchases and smuggling, both likely to be more relevant for higher-value less bulky products. Not reported separately in clearance data are RTDs (ready-to-drink beverages, aka alcopops). Available survey data on off-trade household expenditure on different products shows that RTDs did not feature before 1996, and consumption increased only slowly between 1996 and 1999. Between 1999 and 2002, there was a four-fold increase in RTD beverage volume bought for home consumption, but popularity has decreased almost as rapidly from 2004. In 2009, RTD consumption accounted for only $3 \%$ of total alcohol consumed and is largely confined to young women (National Statistics 2010). It is noteworthy that the average strength of wine increased considerably from c. $11.7 \%$ abv in 1997 to c. $12.9 \%$ abv in 2008 whilst the average strength of beer consumed in the UK has increased only mildly from c. $4 \%$ to c. $4.2 \%$ abv (Public Health Commission 2008).

The UK retains a stronger on-trade culture compared to many other EU countries, with the much-loved social institution of "the local" (ie. the neighbourhood pub). However, there is a strong increase in home consumption, likely to be driven by the increasing discrepancy between on- and off-trade prices (discussed below). For example, on-trade beer sales decreased year-on-year in both absolute volume terms and expressed as share of the beer market. Whilst in $1990,80 \%$ of all beer was sold in the on-trade sector, this had dropped to $54 \%$ by 2008 . At the same time, off-trade volume sales continued to increase until 2006 and have been declining only very modestly since then. Expenditure data confirm the shift between on- and off-trade for all beverage types (DEFRA 2010). Alcohol is bought less frequently in restaurants and only a small proportion of respondents regularly used off-licenses ("bottle shops") (National Statistics 2010e). Studies note the increasing importance of preloading, where young drinkers start drinking cheaper alcohol at home, and continue drinking in the ontrade once they are already quite inebriated (Hughes et al. 2008).

\section{- Problem drinking}

National Statistics commonly use the following thresholds for men and women: lower risk drinkers $(\leq 4 / 3$ units per day or $\leq 21 / 14$ units per week), increasingrisk drinkers (more than these limits but $<50 / 35$ units per week), high-risk or harmful drinkers ( $\geq 50 / 35$ units per week) and binge drinking ( $>8 / 6$ units per day). Trend data on heavy and harmful drinking is available 1992 to 2008, binge drinking data to 1998 to 2008. The latter refers to the proportion of respondents who had one or more binges in the past week (National Statistics 2003a; 2004a; 2005a; 2006a; 2007a; 2008a; 2009a; 2010a).

Heavy and harmful drinking continues to be more prevalent in men compared to 
women, although the gap has been narrowing since the early 1990s. In men, the proportion of binge, hazardous, and harmful drinkers in the adult population has been relatively stable at around $21 \%$, $27 \%$ and $7 \%$, respectively, and did not appear to be influenced much by the recording change in 2006. Because of their wine preference, women are more affected by both increasing underrecording and the sudden correction in 2006. Binge drinking rates increased from $9 \%$ to $15 \%$, hazardous drinking varying between 11\% and $19 \%$ and harmful drinking increasing from $2 \%$ to $4 \%$. Much of the increases appear as step changes in 2006.

During much of the 1990s and early 2000s, binge, heavy and harmful drinking was far more prevalent in younger drinkers than older drinkers. Since then, rates in younger drinkers have decreased and those in older drinkers have remained stable or increased, possibly indicating that the heaviest drinking cohorts have now reached middle-age without decreasing their consumption levels. In men, it is now those aged 45-64 who are most likely to drink at heavy and harmful levels, whereas in women, age differences between those aged 16 to 64 have virtually disappeared.

\section{Underage drinking}

There is no legal age limit to drinking alcohol, but the minimum legal purchasing age is 18 and it is illegal to provide alcohol to someone under the age of 18 (or 16 when accompanied by a responsible adult and drinking with a meal in the on-trade). Underage drinking remains very common in the UK. However, after a long period of steadily increasing alcohol consumption lasting until 2003/4, English school surveys now suggest a decline in the prevalence of lifetime and weekly drinking (see Table 2), with $52 \%$ of $11-15$ year olds reporting lifetime drinking in 2008, down from peak levels of $65 \%$ in 1994; and weekly drinking decreasing from $26 \%$ in 2001 to $18 \%$ in 2008 . Recent trends on volume consumed are somewhat difficult to interpret due to the 2006 change in recording, however, it appears that the average volume of drinking amongst those who do drink may have been increasing. In 2008, there were also high levels of intentional intoxication: Around half of 15-year-old drinkers report drinking with the intention of getting drunk, with $63 \%$ having been drunk at least once. Prevalence, patterns and trends are very similar for boys and girls (National Statistics 2003a; 2004a; 2005a; 2006a; 2007a; 2008a; 2009a; 2010a; National Statistics 2006b; 2007b; 2008b; 2009b; 2010b).

As in adults, on-trade drinking is declining, with pupils in Scotland (where these data are collected) increasingly choosing to drink at home or someone else's home, at parties and outdoors, thus reinforcing the importance of parental monitoring and enforcement of the minimum legal purchasing age in the off-trade.

\section{Trends in alcohol- related harm}

It is beyond the scope of this paper to present trends for the range of alcoholrelated harms in each of the four countries of the UK. Presented are selected England health and crime harm trends that are, on the whole, representative for trends in other harms and areas. 
Table 2. Underage consumption

\begin{tabular}{|c|c|c|c|c|}
\hline Construct & Age & Trend & Narrative trend & Data Source(s) \\
\hline Drinking participation: Lifetime use & $11-15$ & $\pi$ & $\begin{array}{l}\text { Increase to } 2003 / 4 \text {, } \\
\text { then decline }\end{array}$ & NS 2006b-20109b \\
\hline Drinking participation: Lifetime use & $15-16$ & $\rightarrow$ & Stable & ESPAD \\
\hline Drinking participation: Last month use & $15-16$ & עי & $\begin{array}{l}\text { Increase till 1999, } \\
\text { decreases to } 2003 \text { and } \\
2007\end{array}$ & ESPAD \\
\hline Drinking participation: Last week use & $11-15$ & עי & $\begin{array}{l}\text { Increase to 2001, then } \\
\text { decline }\end{array}$ & NS 2006b-2010b \\
\hline On-trade drinking & $11-15$ & $\searrow$ & Decline & NS 2006b-2010b \\
\hline Off-trade drinking & $11-15$ & $\lambda$ & $\begin{array}{l}\text { Increase in drinking at } \\
\text { home, at friends' home } \\
\text { and outdoors }\end{array}$ & NS 2006b-2010b \\
\hline $\begin{array}{l}\text { Alcohol source (\% of pupils obtaining } \\
\text { alcohol from): Off-licenses }\end{array}$ & $13-15$ & 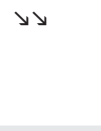 & $\begin{array}{l}\text { Increase } 1996-2002 \text {, } \\
\text { then marked decrease } \\
\text { to } 2008\end{array}$ & SALSUS \\
\hline $\begin{array}{l}\text { Alcohol source (\% of pupils obtaining } \\
\text { alcohol from): Supermarkets and } \\
\text { shops }\end{array}$ & $13-15$ & & $\begin{array}{l}\text { Slight increase } \\
\text { 1996-2002, then slight } \\
\text { decrease to } 2008\end{array}$ & SALSUS \\
\hline $\begin{array}{l}\text { Alcohol source (\% of pupils obtaining } \\
\text { alcohol from): Friends and relatives }\end{array}$ & $13-15$ & $\pi$ & $\begin{array}{l}\text { Marked increase } \\
\text { 1996-2008 }\end{array}$ & SALSUS \\
\hline \multicolumn{5}{|c|}{$\begin{array}{l}\text { Due to the similarity of trends and patterns, not reported separately for girls and boys. } \\
\text { Data Sources: NS (National Statistics 2006b, 2007b, 2008b, 2009b, 2010b) covers England 11-15 year olds; } \\
\text { SALSUS } 2009 \text { covers Scottish } 13 \text { and } 15 \text { year olds reporting trends 1996-2008, ESPAD key results generator } \\
15-16 \text { year olds, } 1995,1997,2003,2007 \text {. }\end{array}$} \\
\hline
\end{tabular}

\section{口 Health}

Alcohol-attributable hospital admissions The key health indicator used by UK policy makers is the rate of hospital admissions for alcohol-related harm per 100,000 population (currently the only national performance indicator related to alcohol). Hospitals are required to report to an online data portal used by the UK National Health Service to collect and share performance information, aggregate data and statutory returns, these data are then used by the Department of Health to estimate the number of per- sons with one or more admissions for an alcohol-attributable disease. In recent year, alcohol-attributable admissions have been increasing at a rate of $11 \%$ year-on-year, with an estimated 945,000 alcohol-attributable admissions in England in 2008/09 (around $7 \%$ of total admissions) (Health Select Committee 2010). The number of hospital admissions of under-16s with a primary or secondary alcohol-related diagnosis increased from 3,870 in $1995 / 6$ to 5,280 in 2005/6 (National Statistics 2007a). It is unclear whether media attention in lat- 
er years might have led to improved recording of alcohol-related diagnoses.

\section{Alcohol-specific mortality}

National Statistics report on alcohol-specific (100\% attributable) rather than alcohol-attributable deaths (National Statistics 2009c; 2009d; 2010d). Against a backdrop of falling overall mortality rates, there have been stark increases in mortality from alcohol-specific causes, with a continued but slowed increase following very rapid increases since the early 1990s. In 2008, the death rate for UK men was 18.7 per 100,000 (9.1 in 1991) and 8.7 per 100,000 for UK women (5.0 in 1991). During the 1990s, the rapidly increasing death rate of the 35-54 age group overtook that of those aged $75+$. In both men and women, the highest death rates are found in those aged 55-74 (45.8/100,000 and 21.5/100,000 in 2008, respectively). Minor changes in coding have not lead to major changes in overall death rates.

The age-standardised death rate per million population for liver disease increased from 76 for men and 49 for women in 1991 to 164 and 86 in 2008 (National Statistics 2009c). Whilst in 1991 alcoholic liver disease accounted for around $37 \%$ of liver disease mortality in those aged $50+$, in 2005 this had risen to $55 \%$ (National Statistics 2010d).

\section{Drinking during pregnancy}

The proportion of mothers who drink repeatedly during pregnancy is high but decreased from $66 \%$ in 1995 to $54 \%$ in 2005 , whilst the proportion of mothers giving up drinking during pregnancy increased from $24 \%$ to $34 \%$ (National Statistics Alcohol 2008a).

\section{Crime}

Trends in all crime and alcoholrelated violent crime

The British Crime Survey, an annual general household survey, is the data source most commonly used to longitudinally track crime in England and Wales (Walker et al. 2009). This survey is not affected by the discontinuities that police crime statistics have seen, with repeated changes to recording rules during the 2000s. Respondents are asked about their experiences of crime in the past year. Crime rates for all types of crime, with the exception of theft from the person, follow the same long-term trends: rates rose steadily during the 1980s and early 1990s and peaked in 1995. Crime then fell substantially until 2004/05 after which time crime rates reduced only slightly.

The indicator used to estimate alcoholrelated crime is the question whether the victim of crime believes that the offender had been under the influence of alcohol at the time of the offence. In 1995, from when the data are available, victims believed that $41 \%$ of violent offenders were under the influence of alcohol, a proportion that rose to $51 \%$ in $2003 / 4$, and stabilised at around $47 \%$ since $2005 / 6$. For $2008 / 9$, it was estimated that 973,000 violent offences were committed under the influence of alcohol (Walker et al. 2009).

\section{Enforcement of alcohol-related legislation}

Many alcohol-related laws are not enforced by police. Only few licensees have been prosecuted for selling alcohol to an intoxicated person since 2005, despite this being illegal under the Licensing Act 2003 (UK Government 2005). There has also been a $75 \%$ decrease in convictions and 
Table 3. Alcohol availability

\begin{tabular}{lllll}
\hline Construct & Breakdowns & Trend & Narrative trend & Source \\
\hline Alcohol affordability & Off-trade beer & $\pi$ & Marked increase & NS Consumer Price Index \\
& Off-trade wine & $\lambda \pi$ & Marked increase & \\
& On-trade beer & $\lambda$ & Increase & \\
& On-trade wine & $\nearrow$ & Increase & \\
Number of licensed & Full on-licenses & $\lambda \rightarrow$ & Increase till 2004. Then & BBPA \\
premises & (pubs etc) & & probably stable. & \\
& Partial licenses & $\rightarrow$ & Stable (slight increase in & \\
& (restaurants etc) & & Scotland) & \\
& Clubs & $\searrow$ & Decrease & \\
& Off-licenses & $\rightarrow$ & Stable (slight increase in & \\
& & & Scotland) & \\
\hline
\end{tabular}

Note. $\rightarrow$ Stable $\searrow$ Decrease $\pi$ Increase ス Marked increase $\searrow$ Marked decrease

Data Sources: Licensing law. BBPA Statistical Handbooks 2007, 2009 (reporting data from Home Office and DCMS from 1990. Recoding change in England and Wales in 2004/5). NS Consumer Price Index (National Statistics 2010c): Since 1990. Affordability: Alcohol prices standardised against inflation and average disposable income.

cautions for drunk and disorderly behaviour since the 1980s (BBPA 2009).

\section{Drink driving}

Yearly drink driving traffic casualties, in line with all traffic casualties, have decreased markedly since 1990 (all casualties: 20,400 to 13,000; fatalities: 760 to 430 in 2007). However, the proportion of accidents involving illegal alcohol levels fluctuates between 5 and 7\% (DfT 2009). Breath tests were carried out for less than $30 \%$ of drivers involved in injury accidents until 1996, at which point new police regulations encouraged breath testing at the scene, increasing the proportion of drivers tested to around 55\% (BBPA 09). The proportion of positive breath tests has been stable since 1990 at around $2-2.5 \%$.

\section{Some proximal contributors to these changes: Availability of alcohol and social attitudes}

Availability is likely to be an important contributor to trends, as are wider "drinking culture" factors. This section provides an overview of development in the "three As" of availability - physical availability, describing trends in the number and types of outlets and hours of sale, economic availability, looking at trends in alcohol affordability compared to inflation and average income, and "cognitive” availability via advertising, as well as changed attitudes.

\section{Physical availability}

Physical availability to adults

Number and types of outlets: The total number of licensed premises in England and Wales seems to have been fairly sta- 
ble during the 1990s and 2000s at around 200,000. The number of off-licensed premises was stable at around 55,000 up to 2004. The number of full on-licenses is reported to have increased from around 83,000 in 1990 to 91,000 in 2004 (Home Office, DCMS and Nielsen data, reported in BBPA 2009). Data relating to 2007 to 2009 are not directly comparable because of a recording change. These again show relatively stable numbers at around 124,000 on-licenses (some of which are also licensed to sell for home consumption) and 47,000 off-licenses (DCMS 2009). More disaggregated data on outlet type or capacity is not available. The developments seen here do not appear to match the observed shift from on- to off-trade consumption, nor the marked shift from off-license to supermarket purchasing.

Licensing: A key change concerning alcohol licensing in England and Wales was the Licensing Act 2003 (which came into force in November 2005). Licensing laws prior to 2005 allowed alcohol to be sold until 11pm from Monday to Saturday, and 10:30pm on a Sunday, in both on-trade and off-trade sector (off-trade Sunday trading was restricted until 1995, when all-day Sunday trading was first introduced). Since 2005, the four licensing objectives in England have been the prevention of crime and disorder, public safety, prevention of public nuisance, and the protection of children from harm, with no provision for public health considerations. Fixed licensing hours were abandoned, with the explicit aim to favour a more continental drinking culture, to prevent the last-minute consumption surge just before $11 \mathrm{pm}$ and to reduce crime by avoiding drunk patrons all leaving premis- es at the same time. Maybe unexpectedly, only a minority of on-license premises opted for a 24-hour license, and most appear to have increased their usual opening times by less than an hour per day (Hough et al. 2008). Information on alcohol sales times in the off-trade, for which the licensing hour changes also apply, is not available. In Scotland, policy changed with the Licensing (Scotland) Act 2005, which replaced the previous legislation in September 2009. The law has an objective to protect public health and there are some attempts to control irresponsible on-trade promotions such as happy hours and buyone-get-one free offers. A visible difference to England and Wales is that alcohol must be displayed in separate areas within shops and supermarkets, rather than being strategically places at the end of aisles, and off-license sales are permitted only between $10 \mathrm{am}$ and $10 \mathrm{pm}$. Compared to the rest of the UK, Northern Ireland has historically been a low use area because of religious and cultural norms. It has traditionally had far stricter licensing laws, and whilst licensing liberalization has been discussed it has not implemented. A new on- or off-license is only granted if another is being surrendered at the same time, and if the court is satisfied that there is not already adequate provision, thus providing a strict control on outlet density.

\section{Physical availability to children}

It is illegal in the UK to sell alcohol to those under the age of 18, to buy alcohol on behalf of someone under that age, or for anyone under 18 to attempt to buy alcohol and in recent years, many alcohol retailers have committed to asking for ageverification of anyone who appears to be 
Table 4. Alcohol-related harm

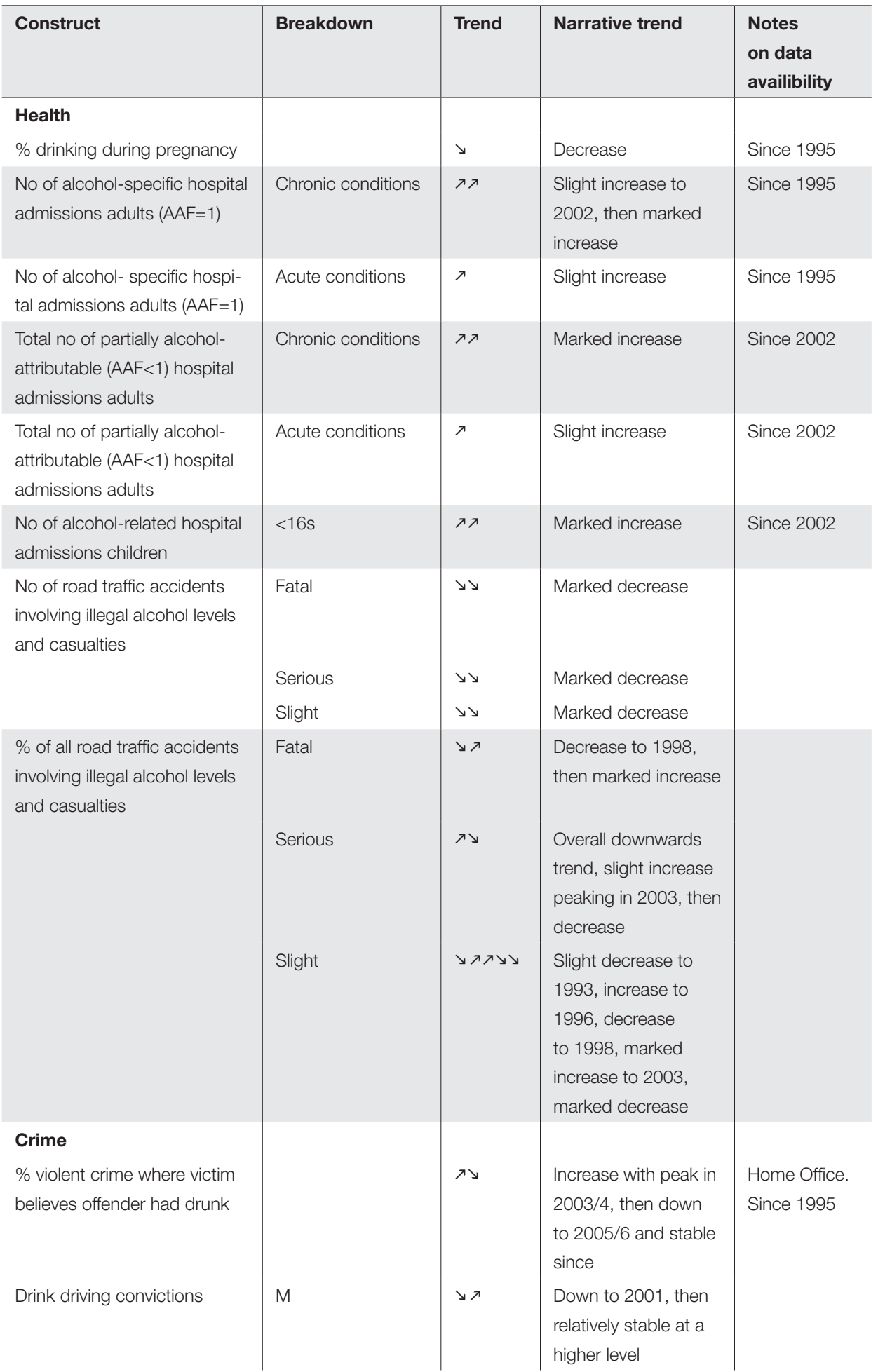




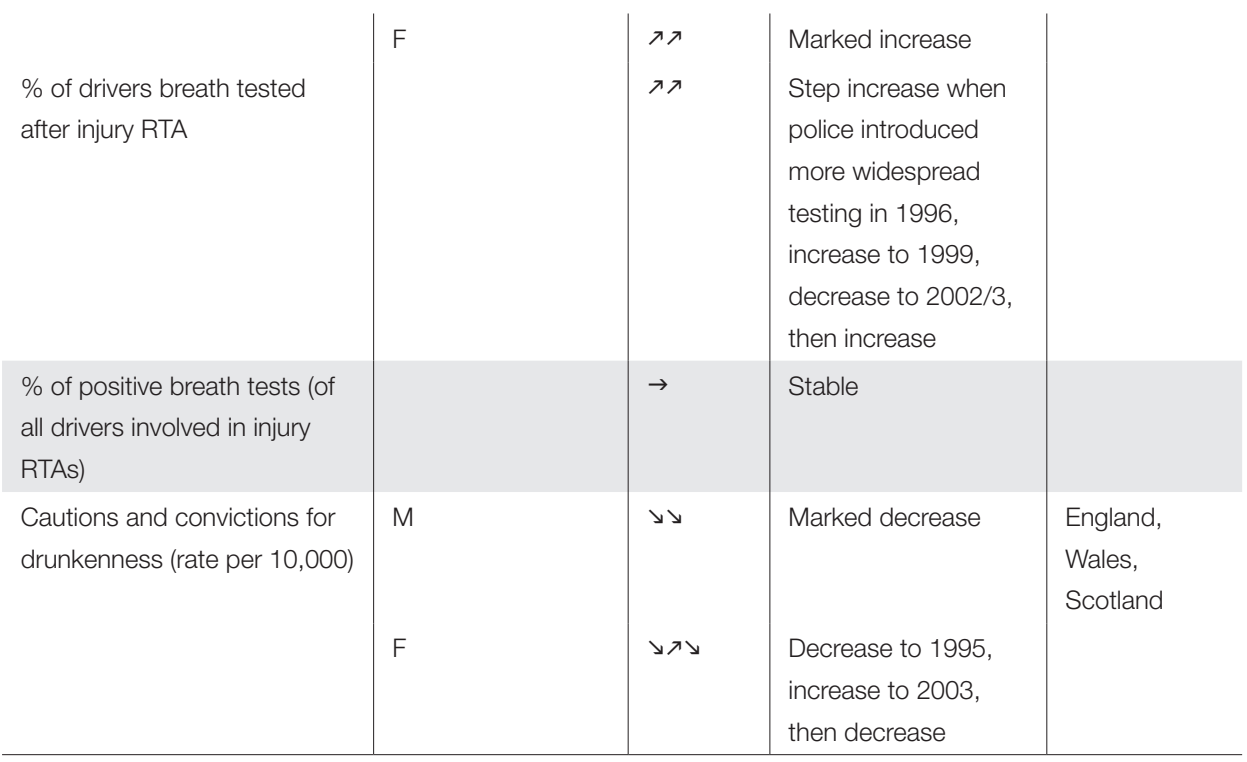

Sources: Unless otherwise stated: National Statistics 2003a to 20010a. Data available from 1990 unless otherwise stated. Home Office 2009. British Crime Survey Report, data from 1995.

under the age of 21. The publicity around this may have contributed to a consistent decline in pupils attempting to buy from off-licenses, although buying from other shops and supermarkets has remained relatively stable (National Statistics 2008a; SALSUS 2009).

Underage children's' experiences of how easy it is to obtain alcohol have not changed over the last two decades. $14 \%$ of 11 -year-olds and $69 \%$ of 15 -year olds in a survey had obtained alcohol in the past week (National Statistics 2008a). However, there has been a shift in sources of alcohol, with parents and friends now the dominant source. Buying or attempting to buy alcohol in the on-or off-licensed sector is less common and has been decreasing. In 2008, asked about past-week purchasing, $10 \%$ of Scottish 13-year-olds and $17 \%$ of 15 -year-olds said they had attempted to buy alcohol in the off-trade. In both age groups, $70 \%$ of off-trade purchase attempts were successful. $4 \%$ of 13 -yearolds and $12 \%$ of 15 -year-olds said they had attempted to buy alcohol in the on-trade, $75 \%$ of purchase attempts of 13 -year-olds and $83 \%$ of purchase attempts by 15 -yearolds were successful (SALSUS 2009).

\section{Affordability}

According to an affordability index produced by National Statistics, the affordability of alcohol has increased steadily between 1987 and 2007, after taking into consideration inflation and rises in income (National Statistics 2008a). Duty increases were irregular, inconsistent between beverage types, and frequently fell short of the level of inflation (HMRC 2010). In the past two years, a series of small across-product duty rises have been implemented, but supermarkets continue to use alcohol as loss-leaders (aka below-cost selling) and 
the degree to which tax increases have been passed through to the consumer is unclear. There is a wide gap between the on-trade and the off-trade sectors, with the affordability of wines and beers increasing by $49 \%$ and $39 \%$ respectively in the ontrade but by $129 \%$ and $153 \%$, respectively, in the off-trade (analysis using data from National Statistics 2010c). At least in the on-trade, the driving force is not alcohol price per se, which has been rising, but that the prices of many consumer goods, including alcohol, have not kept up with increases in disposable income.

\section{Advertising and marketing}

There is a mixture between voluntary and statutory regulation for advertising. Ofcom is a statutory regulator of the UK communications industries, with responsibilities for television, radio, telecommunications and wireless communications services. Ofcom was established in December 2003 and replaced separate statutory organizations responsible for television, radio, broadcasting standards, telecommunications. The Advertising Standards Authority (ASA) is a self-regulatory body established in 1962 by the marketing industry to ensure that non-broadcast advertisements comply with the British Code of Advertising, Sales Promotion and Direct Marketing. In November 2004, after a period of review and consultation, Ofcom decided that a co-regulatory approach to broadcast advertising regulation would be preferable to the existing fragmented statutory system and delegated day-to-day responsibility for broadcast advertising to the ASA. At the same time, responsibility for the TV and Radio Advertising Standards Codes themselves was delegated to the Broadcast
Committee of Advertising Practice (BCAP), an industry rule-making body, comprising advertisers, agencies and broadcast media. Since late 2005, codes for both broadcast and non-broadcast media include a clause that alcohol advertisements 'must not be likely to appeal strongly to people under 18'. ASA runs an annual compliance survey, which regularly finds very few ads $(<1 \%)$ in breach of rules, although a survey with young people before and after the 2005 code change showed that children continue to find alcohol adverts attractive (Ofcom/ASA 2007). Product placements (paid-for brand-specific product portrayals embedded in TV, cinema, or radio programmes or internet games) are permitted in UK productions from this year, however, after some debate, alcohol product placements remain prohibited.

\section{Attitudes towards alcohol} and alcohol policy

The general public are as inconsistent in their attitudes towards alcohol as politicians and the media. Whilst in 2007, twothirds of adults responding to the General Household Survey believed that 'drinking is a major part of the British way of life', there was also strong agreement that people in other parts of Europe drink more sensibly than people here. Less than $10 \%$ felt that 'there is nothing wrong with people getting drunk regularly'. However, there is a strong emphasis on individual responsibility. In European comparisons, UK citizens tend to be amongst the least supportive of government intervention (Eurobarometer 2010) and in 2007, there was little enthusiasm for higher taxation to encourage people to drink less (23\% of men and $32 \%$ of women, National Statistics 2010d). 
Interestingly, recent data show that children are becoming less tolerant of drinking and drunkenness among their peers. Between 2003 and 2008, the proportion of 11-15 year olds agreeing that it was OK for someone of their age to drink once a week fell from $46 \%$ to $36 \%$, and the proportion who thought it OK for someone of their age to get drunk once a week from $20 \%$ to $12 \%$ (National Statistics 2006b; 2007b; 2008b; 2009b; 2010b). It is possible that this is a first indication of shifting social norms - similar as that seen for tobacco several years earlier. This might have been linked to media attention that is increasingly focused on the negative effects of underage drinking, and fewer pro-drinking role models in the friendship network due to increasing abstention rates.

\section{Major distal influences: The role of national and international politics, the alcohol industry and the media}

This penultimate section will investigate the development of the political, industrial and media landscape during the 1990s and 2000s, to provide information on the political and societal context in which consumption and harm changes could occur. Readers should note that this section, more than others, is based on the author's and informants' interpretations of the situation.

\section{- Political developments}

There was little in the way of cross-governmental alcohol policy until 1999. In 1999, a Green Paper committed Government to the development of a strategy by 2000 (UK Government 1999) and set out aims to encourage people who drink to do so sensibly to avoid alcohol-related problems, to protect individuals and communities from anti-social and criminal behaviour and to provide specialist treatment services. This first paper set the tone for all strategy developments since then, by announcing the intention to work in partnership with the alcohol industry. The first alcohol strategy, Alcohol Harm Reduction Strategy for England (AHRSE), published in 2004 and updated (Safe.Sensible.Social) in 2007 (Cabinet Office 2004; Department of Health et al. 2007), and has been described as an example of how a policy document can be weakened during a lengthy consultation process with strong industry input (Room 2004; Harkins 2010). A line in the strategy reads: "There is no direct correlation between drinking behaviour and the harm experienced or caused by individuals" and the final strategy does not refer to the testimonies from 17 independent experts who provided evidence and who highlighted the need for action on alcohol pricing and availability (Harkins 2010). Instead, the only alcohol expert group mentioned in the final strategy was the industry-funded Portman Group (see section 4.2). A common verdict in scientific circles has been that the strategy is dominated by policies that are high profile, cheap and ineffective, with none of the policies that are internationally considered effective in reducing alcohol consumption (Drummond 2004; Plant 2004; Room 2004).

However, since then, alcohol has undeniably moved up the political agenda, helped by rising levels of consumption and harm, avid media interest, and several new national performance indicators. Most notably, the target of "reducing the rate of rise in alcohol-related hospital admissions" was introduced by both NHS 
and Home Office in 2007. A discussion of the most recent developments follows below in the final section.

\section{Changes in the political landscape: The role of devolved governments, EU and WHO}

In 1997/8, the UK devolution process saw the introduction of governments in Scotland, Wales, and Northern Ireland (temporarily suspended in NI 2002-07, but reinstated in 2006). On the whole, this has increased UK attention to alcohol, and effective alcohol policies, with the devolved administrations often taking a more proactive approach to public health, including controlling alcohol related harm. Several newspaper reports suggest that where no devolved powers exist, as for example with taxation, Scottish and Welsh politicians have tried to influence the Westminster government to take action. Some examples of policy differences are provided below when discussing pricing and availability policies.

Until recently, the main international influence relating to alcohol were EU trade liberalisation, leading to general food and drink trade growth, subsidy of the winemaking industry as part of the Common Agricultural Policy, and encouragement for private cross-border purchasing. EU trade policies are starting to present challenges for UK policies in the areas of alcohol pricing control and product labelling. EU and WHO alcohol policies have influenced UK policy to only a limited degree, but the influence is likely to increase in the future. The first EU alcohol strategy was introduced in 2007 and has a strong focus on voluntary social responsibility agreements as primary responses. The one more stringent recommendation, to set the BAC limit for drivers at $0.5 \mathrm{~g} / \mathrm{L}$, has so far not been adopted by UK policy makers. There is however a strengthening EU role in the development and dissemination of evidence for policy, with comparisons between countries now regularly used in public debate. Similarly, WHO tends to serve mainly as a reference point for policy effectiveness evidence. This role should increase further with the new Global Alcohol Strategy. While WHO does not propose policies for particular countries, this may make it harder to dismiss evidence-based policies in future. Finally in late 2010, the new Tory Health Secretary has annouced a key role for the food and drinks industry in influencing public health policy via so-called responsibility clear networks.

\section{- Industry influences}

As in many countries, the alcohol industries continue to have a very significant influence on policy developments. This was also criticised by the parliamentary Health Select Committee (2010): "We are concerned that government policies are much closer to, and too influenced by, those of the drinks industry and the supermarkets than those of expert health professionals." The former Labour government's response to this stated: "The Government's general approach to legislation in the alcohol industry is first to seek commitments to self-regulation, wherever this may be effective and feasible, and it is right that we continue to do so." Government-funded researchers have faced pre-appointed reference groups including industry bodies. Refusal to work in this way by pointing to the threat to independence is respected, but the approach could be seen as indica- 
tive of close relations between (some sectors of) government and industry.

One of the main lobbying groups is the industry-funded Portman Group, established in 1989 with the "purpose of promoting sensible drinking, helping to prevent alcohol misuse and abuse, and to help generate a better understanding of alcoholrelated issues". It was heavily criticised for paying academics to anonymously attack a review of alcohol policy effectiveness for the WHO in 1994 (Harkins 2010). Despite this, it took on the role of industry watchdog in 1996, launching a Voluntary Code of Practice on the Naming, Packaging and Merchandising of Alcoholic Drinks. The Portman Group continues to shape government strategy with calls for educational interventions, to avoid punishing the 'vast majority of sensible drinkers', to recognise individual responsibility for harm, and by rejecting influences of pricing and advertising on consumption (Harkin 2010).

In 2007, the Drinkaware Trust - an industry-funded but independent charity with trustees drawn from academia and social organisations - was launched with the objective of positively changing public behaviour and the national drinking culture, probably in part as a response to increased concern about rising rates of alcohol-related health harm and antisocial behaviour in downtown areas. It took over all educational activities from the Portman Group and its weblink now appears together with the recommended drinking message and "enjoy responsibly" on all beverages carrying labels.

Other key lobbying organisations are the Wine and Spirit Trade Association, the British Beer and Pub Association, and the Scottish Whisky Association. These players regularly respond to (and in some instances dominate) Government and NHS consultation exercises. Examples are recent consultations on minimum pricing, promotion restrictions, advertising restrictions and the recently published NICE public health guidelines on alcohol prevention (National Institute for Health and (Clinical Excellence 2010). Finally, in late 2010, the new Torn Health Secretary has announced a key role for the food and drinks industry in influencing publichealth policy via so-called 'responsibility deal' networks.

\section{- Media and public discourse}

There has been little formal UK research on factual media reporting on alcohol, drinking practices, alcohol policy, and alcohol-related problems (Hansen \& Gunter 2007). It appears that media portrayals of alcohol have rarely reflected a balanced view of alcohol use, or of the range of drinking contexts. They tend to link alcohol dependence to deprivation and homelessness, and binge drinking, especially amongst young women, to deviance. However, at the same time, drinking to intoxication is regularly portrayed as normal youth behaviour rather than the exception (see Measham \& Brain 2005), alongside a view that excessive drinking increasingly pervades the society, with negative consequences in terms of anti-social and nuisance behaviour. Where surveys find increases in consumption or harms this seems to receive far more coverage than when trends are stabilising.

The media focus on binge drinking and anti-social behaviour has led to a strong focus of drinking as a criminal justice issue, an issue to do more with the on-trade than 
the off-trade, and a young people's rather than a population-wide problem. This has to a degree translated into governmental responses - for example, there is a 2008 youth alcohol strategy and most policies that have been implemented or discussed are more concerned with tackling on-trade drinking. Finally, there is regular emphasis in public and political debates on how alcohol is part of our culture, and that this is something that it would be difficult, and possibly undesirable, to change.

\section{The current situation: policy initiatives}

There has been much political interest in alcohol during the past five years, and this final section provides an overview of the current (May 2010) state of policy initiatives.

\section{- Policies on availability and price}

There has been mounting external pressure on government to act on price and availability. The parliamentary health select committee released a report on its alcohol inquiry in early 2010 calling for action (Health Select Committee 2010). A powerful statutory health body, the National Institute for Health and Clinical Excellence, has backed pricing and availability restrictions (National Institute for Health and Clinical Excellence 2010). There are regular calls for action from the medical profession, including the Government's outgoing Chief Medical Officer, the Royal College of Physicians and the BMA; from most major health charities and also the Association of Chief Policy Officers. The industry is divided, with some elements favouring action on price, especially in the on-trade sector, which finds that it cannot compete with supermarket pricing. However, in the written response to the health select committee report (UK Government 2010), the then Labour Government confirmed that it was not planning to follow recommendations to implement advertising controls, availability restrictions (except targeting underage drinking), tax by beverage strength or minimum pricing. The industry-friendly new ConservativeLiberal coalition government places a clear emphasis on individual responsibility, treatment and local solutions including increased local licensing powers rather than national policy action.

Taxation: Government has repeatedly confirmed that it does not consider alcohol taxation in public health terms. In 2010, it stated that "the primary purpose of alcohol duty is to raise funds for the public finances... Where there is evidence that tax policy is an effective approach to support wider Government policy... the Treasury could consider its use as long as it was consistent with the public finances." Alcohol duty receipts have risen in monetary terms, but at the same time they now make up the smallest ever proportion of government tax revenue (falling from $5.4 \%$ in $1993 / 4$ to $3.6 \%$ in $2006 / 7$, recovering to $3.9 \%$ in 2009) (BBPA 2009). In 2008, the Treasury announced a duty escalator, which saw a series of small duty increases, and duty is set to increase at $2 \%$ above inflation every year until 2013, unless this is abandoned by the new government. A recent announcement to bring cider duty rates in line with other beverage types through a $10 \%$ oneoff increase has quickly been withdrawn. A specific point to consider in the UK is that of pass-through of tax rises by supermarkets, which may have both the capacity 
and motivation to absorb tax rises and to continue to use cheap alcohol to draw customers into the store.

Minimum pricing: The general election brought in a new Conservative-Liberal Democrat coalition government in May 2010. In England, one of the ruling parties, the Liberal Democrats, had backed the policy before the general election, but the policy is now not mentioned in their new coalition agreement with the Conservatives. Both Scotland and Wales were actively considering minimum pricing, with a Scottish bill setting the minimum price of alcohol to $45 \mathrm{p}$ per $10 \mathrm{ml}$ unit (among other policies around licensing and a social responsibility levy). However, the minority SNP government failed to secure support from the opposition parties and the final alcohol bill does not include minimum pricing.

Banning price promotions: In Scotland, new licensing legislation came into force in September 2009 and bans irresponsible on-trade drinks promotions and in supermarkets, alcohol must be located in separate areas. A bill outlawing off-trade quantity discounts was passed by parliament in November 2010. In England, a mandatory retail code came into force in April 2010 to stop the most irresponsible promotions in the on-trade sector (e.g. "all you can drink” offers). However, strong opposition from the drinks industry, supported by the business secretary, meant that proposed sections on outlawing happy-hour promotions were dropped at the last minute.

Banning below cost selling: A sales practice that is widely criticised is that of selling alcohol below cost (i.e. a negative gross margin). According to self-reports by the main supermarket chains, 6 out of 7 had sold al- cohol below cost in the past year, with up to $3 \%$ of retailers' total revenue coming from such loss leaders (Competition Commission 2008). Activity clustered around public holidays and sports events, which are times of fierce competition between retailers. The new government's coalition agreement contained a pledge to ban loss-leading and to consider other price policy options, however, a more recent announcement stated that no action would be taken until 2012 and then only 'if necessary'.

Availability: The Minimum Legal Purchasing Age is 18, or 16 when accompanied by a responsible adult and drinking with a meal. In 2008, the Chief Medical Officer recommended an alcohol-free childhood until age 15, sparking controversy in the media and amongst parents. Whilst not explicitly designed as an availability policy, the Policing \& Crime Act 2009 (England) created the legislative framework that allowed the introduction of a new mandatory code of practice with new powers to confiscate alcohol from underage drinkers. Also, smaller measures of beers, wine and spirits must be made available from October 2010. The new Scottish legislation means that licensing boards there are encouraged to consider "overprovision". Some global retail chains have recently been prevented from expanding store space to sell alcohol. This could lead to costly court actions and it remains to be seen whether licensing bodies' decisions are upheld at appeal. A further licensing review is being undertaken by the new Government.

\section{Screening and brief interventions (SCBI)}

Positive developments have occurred in the delivery of SCBI. Policies seem gener- 
ally less contentious if they are fully within the remit of one government department and there is no industry involvement. A major trial of SCBI in primary care and emergency settings has been funded, with promising early results. Considerable financial incentives were introduced in 2008 for primary care physicians to screen new patients at registration, a scheme due to run until March 2011. Medical, nursing and midwifery degree providers are now required to cover smoking, drinking and drug use in the curriculum and e-learning modules for brief advice have been created for existing primary care and hospital staff. In 2008, a new campaign was launched by the Ministry of Justice to encourage staff to provide SCBI for offenders whose alcohol consumption contributes to their offending.

However, these changes appear to be too recent to be reflected in patient experience or GP training levels. In 2009, only $10 \%$ of male drinkers, and even fewer female drinkers, had discussed alcohol with a medical professional, unchanged since 2000 (National Statistics 2010d). On average, GPs had received no more postgraduate training by 2009 than they had in 1999 ( $<4$ hours in total), but they rated alcohol and other lifestyle behaviours as more of a priority and they were also more prepared to provide interventions (Lock et al. 2010).

\section{- Primary care and specialist treatment}

In 2006, treatment and referral guidelines for specialist alcohol treatment were revised after studies reported that only between 5 and $10 \%$ of alcohol dependent people accessed treatment services and retention was generally poor. From 2008, this has been supported by routine data collection on alcohol treatment provision, as well as the appointment of regional alcohol managers who monitor local commissioning and service delivery. Survey estimates have put the number of dependent alcohol users in the UK at $1.1 \mathrm{~m}$ (with a further $7 \mathrm{~m}$ drinking above recommended limits), with about 100,000 users in treatment at any one time in 2009 (NDEC, 2010).

\section{Education and information}

Arguably, the major approach to tackling population-level overconsumption in the UK is to provide education, information, and alcohol content labelling. A government report in 1995 reframed the sensible drinking message from weekly to daily limits, expressed in alcohol units per day (no more than 3-4 for men and 2-3 for women). It recommended a campaign to promote the new message, however, this only really started in 2006/7, when a major multi-million-pound public education campaign "Know your limits" was launched which targeted binge drinkers, underage drinkers, dependent drinkers and pregnant women. Over time, the terminology changed from "safe" to "sensible" to "lower-risk" drinking limits. For the complex recommendation to be effective, drinkers need to know not only the recommended limit but also how to relate their consumption to the equivalent in UK alcohol units. Knowledge has clearly improved over recent years: In 2009, 90\% of adults were aware that the UK has a unit system (up from 79\% in 1997), 75\% knew there were recommended drinking limits and $65 \%$ knew the approximate unit content of their drinks (National Statistics 2010a). However, only a fifth knew what the relevant recommendation was for 
them and only a minority of less than $15 \%$ of those aware of the unit system said they attempted to keep track of the number of units consumed.

In May 2007, the government negotiated a new voluntary agreement with industry on the introduction of labels on bottles and cans by the end of 2008. Two studies in 2008 showed that large parts of industry failed to comply, and government threatened that they were considering the legal and practical feasibility of a mandatory code. A follow-up study in 2009 showed only minor improvements, with $85 \%$ of products still not labelled correctly. The industry appeared largely unconcerned with the findings, with the largest grocery chain admitting they had not introduced full labelling even on own-brand products. Again, the Labour Government's response was that they would consider taking mandatory action "if necessary".

\section{- Policies tackling drink-driving}

The UK has one of the highest drink driving limits in Europe, a blood alcohol concentration of $80 \mathrm{mg}$ per $100 \mathrm{ml}$ blood with no special limit for young drivers after a prolonged consultation exercise about a reduction to 50mg during 1998-2000. Random breath testing is not carried out and there is no routine breath testing at the scenes of accidents. If found guilty of drink-driving, penalties are significant, with a license suspension for at least one year and causing death whilst intoxicated punishable with up to 14 years imprisonment. Two media campaigns per year are run by the Department for Transport. Given downward trends in road deaths there is limited public concern or political interest in the topic.

\section{Discussion}

The UK has seen significant changes in the patterns of consumption during the 1990s and early 2000s, which go some way to explain the rapid increase in alcohol related admissions and other heavy end consequences in the context of falling per capita consumption. These include a rise in heavy episodic drinking, increasing preference of higher alcohol content beverages and a polarisation of the distribution of consumption in the population where heavy drinkers drink even higher volumes whilst moderate drinkers appear to have decreased their average intake. Together with a lagged effect on harm these may all play a role in driving the continuing increase in alcohol related morbidity and mortality, despite a recent downturn in population level consumption.

There is no consensus about why average consumption levels have been decreasing since about 2004, a trend especially pronounced in children and young adults under the age of 25. Whilst many alcohol-related trends changed direction between 2003 and 2006, several data recording mechanisms also changed during this time (e.g. all government surveys measuring consumption, counting of premise licenses, crime counting rules), making interpretation of trends more difficult. However, a similar rise-and-fall trend is consistently observed across individual and aggregate-level data sources and in different cuts of the population, thus it is unlikely to be explained by changes in methods or recording practices.

Some have argued that changes may have been prompted by the introduction of the Licensing Act 2003 in 2005, but the evidence for this is relatively weak. Any 
effects of the Act appear to have been small with only minor changes to actual availability (Hough et al. 2008). In some instances, changed trajectories precede the Licensing Act, and quite often, similar trends are observed in Scotland, where licensing reforms did not come into force until 2009. No rigorous scientific evaluations, for example using interrupted time series methods with Scotland as a comparison jurisdiction, were commissioned prior to the introduction but there have been several attempts to retrospectively quantify potential impacts. There were no consistent changes in assault trends, harassment offences or criminal damage (Babb 2007; Hough et al. 2008), although there have been potential increases in alcoholrelated emergency admissions (Newton et al. 2008).

Except for public education campaigns, no other major alcohol policies were introduced during 2003-2007. Availability appears to have remained fairly stable, and affordability continued to increase. Of course it is not possible to say whether consumption decreases would have been more pronounced had affordability decreased, but there were no sharp price rises or availability restrictions that explain the trend change in consumption.

A relevant policy may have been the ban of smoking in public places that came into force in Scotland in March 2006, Wales and Northern Ireland in April 2007 and England in July 2007, with wide media coverage before implementation. Nielsen (2007), an independent market research company, reported that in the year after the introduction of the Scottish smoking ban, on-trade alcohol sales volume in Scotland decreased by $5 \%$ more compared to England. However, whilst beer sales dropped, wine sales continued to rise. In English surveys (SOS 2009), most pub drinkers said that the ban had had little effect on their drinking. However, women and young drinkers tended to increase and men and older drinkers to reduce their visits to pubs. Recent trends show a sharp decrease in smoking in younger age groups, and this young non-smoking generation may well prefer the new smoke-free environment. This suggests that smoking bans may have contributed to a shift in the type of consumers frequenting the ontrade. Even before the smoking bans, since 1997, increasing proportions of smokers have stopped smoking in front of children and non-smoking parents do no longer allow smoking in their home. Children's smoking rates and acceptance of smoking dropped over the same period. Given the strong relationship between youth smoking and drinking, this might have contributed to the decreased alcohol participation and less favourable attitudes towards alcohol observed in under-25s.

However, studies on other problem behaviours among adolescents have generally observed that increases in emotional and behavioural problems as well as rates of cannabis use in the last quarter of the twentieth century did not continue in the new millennium (Maughan et al. 2008; National Statistics 2010b). This may indicate that more wide-ranging social change has contributed to the current reversal of trends in alcohol consumption, but the exact mechanisms are as yet poorly understood.

In terms of policy changes in the UK, alcohol has only developed into a major focus of policy makers' (and media) inter- 
est in the past three years. Since a recent change in the national government and the increasing focus on the economic situation, it appears that some of the momentum for policy change, especially on pricing, promotion and availability, may have been lost.

\section{REFERENCES}

Babb, P. (2007): Violent crime disorder and criminal damage since the introduction of the Licensing Act 2003, Home Office Report 16/07. Available from http://rds. homeoffice.gov.uk/rds/pdfs07/rdsolr1607. pdf (last accessed 1 Oct 2010)

BBPA/British Beer and Pub Association 2007, 2009. A compilation of drinks industry statistics. Statistical Handbooks

Cabinet Office (2004). Alcohol Harm Reduction Strategy for England. Available from http://www.cabinetoffice.gov.uk/media/ cabinetoffice/strategy/assets/caboffce $\% 20$ alcoholhar.pdf (last accessed 1 Oct 2010)

BMA Board of Science (2008): Alcohol misuse: tackling the UK epidemic. http://www. bma.org.uk/images/Alcoholmisuse_tcm41147192.pdf (last accessed 1 Oct 2010)

Competition Commission (2008): Groceries Market Investigation. Final Report. Appendix 5.6. Below-cost selling. Available from http://www.competition-commission.org. uk/rep_pub/reports/2008/fulltext/538_5_6. pdf (last accessed 1 Oct 2010)

DCMS (2009): Alcohol, Entertainment and Late Night Refreshment Licensing, England and Wales. Available from http://data.gov. uk/dataset/alcohol_entertainment_and_ late_night_refreshment_licensing (last accessed 1 Oct 2010)

DEFRA (2010): Family Food Datasets. Department for Environment, Food and Rural Affairs. Available from http://www.defra. gov.uk/evidence/statistics/foodfarm/food/
Petra Sylvia Meier, professor

School of Health and Related Research

(ScHARR)

University of Sheffield, UK

E-mail: p.meier@sheffield.ac.uk familyfood/documents/index.htm (last accessed 1 Oct 2010)

DfT (2009): Reported Road Casualties in Great Britain: 2008 provisional estimates for accidents involving illegal alcohol levels. Available from Department for Transport http://webarchive.nationalarchives.gov.uk/+/http://www.dft.gov.uk/ adobepdf/162469/221412/221549/399405/ rcgb08drinkdrive.pdf (last accessed 1 Oct 2010)

Department of Health, Home Office, Department for Education and Skills, Department for Culture, Media and Sport (2007): Safe. Sensible. Social. The next steps in the National Alcohol Strategy

Drummond, C. (2004): An alcohol strategy for England: the good, the bad and the ugly. Alcohol and Alcoholism 39: 377-379

ESPAD European School Survey Project on Alcohol and Other Drugs. Online key results generator. Available from http:// www.espad.org/keyresult-generator. (last accessed 1 Oct 2010)

Eurobarometer 2010. EU citizens' attitudes towards alcohol. EB72.3 (No 331). Available from: http://ec.europa.eu/public_opinion/ archives/eb_special_en.htm (last accessed 1 Oct 2010)

Hansen, A. \& Gunter, B. (2007): Constructing public and political discourse on alcohol issues. Alcohol \& Alcoholism 42: 150-157

Harkins, C. (2010): The Portman Group. BMJ 2010;340:b5659, doi: 10.1136/bmj.b5659 
Health Select Committee (2010): Alcohol.

First Report of Session 2009-10. Volume 1.

Available from http://www.publications.

parliament.uk/pa/cm200910/cmselect/

cmhealth/151/151i.pdf (last accessed 1

October 2010)

HMRC (2010): Alcohol Factsheet March 2010

Available from: https://www.uktradeinfo. com/index.cfm?task=factalcohol\&hasFlash Player=true (last accessed 1 Oct 2010)

Home Office Statistical Bulletin (2009): Crime in England and Wales 2008/09. Volume 1. Findings from the British Crime Survey and police recorded crime. Available from http://www.homeoffice.gov.uk/rds/pdfs09/ hosb1109vol1.pdf (last accessed 1 Oct 2010)

Hough, M. \& Hunter, G. \& Jacobson, J. \& Cossalter, S. (2008): The impact of the Licensing Act 2003 on levels of crime and disorder: an evaluation. Home Office Research Report 04. London: Home Office

Hughes, K. \& Anderson, Z. \& Morleo, M. \& Bellis, M.A. (2008): Alcohol, nightlife and violence: the relative, contributions of drinking before and during nights out to negative health and criminal justice outcomes. Addiction 103: 60-65

Lock, D. \& Wilson, G. \& Kaner, E. \& Cassidy, P. \& Christie, M.M. \& Heather, N. (2010): A survey of general practitioners' knowledge, attitudes and practices regarding the prevention and management of alcohol-related problems: an update of a World Health Organisation survey ten years on. Available from http://www.aerc.org.uk/documents/ pdfs/finalReports/AERC_FinalReport_0058. pdf (last accessed 1 Oct 2010)

Maughan, B. \& Collishaw, S. \& Meltzer, H. \& Goodman, R. (2008): Recent trends in UK child and adolescent mental health. Soc Psychiatry Psychiatr Epidemiol 43 (4): 305-310

Measham, F. \& Brain, K. (2005): 'Binge' drinking, British alcohol policy and the new culture of intoxication. Crime Media Culture 1: 262-283

Meier, P. \& Brennan, A. \& Purshouse, P. (2010): Policy options for alcohol price regulation: the importance of modelling population heterogeneity. Addiction 105: 383-393
National Statistics: Alcohol (2003a): Statistics on Alcohol, England. Published by the NHS Information Centre for Health and Social Care, Leeds

National Statistics: Alcohol (2004a): Statistics on Alcohol, England. Published by the NHS Information Centre for Health and Social Care, Leeds

National Statistics: Alcohol (2005a): Statistics on Alcohol, England. Published by the NHS Information Centre for Health and Social Care, Leeds

National Statistics: Alcohol (2006a): Statistics on Alcohol, England. Published by the NHS Information Centre for Health and Social Care, Leeds

National Statistics (2006b): Smoking, drinking and drug use among young people in England. Edited by Fuller, E. Published by the NHS Information Centre for Health and Social Care, Leeds

National Statistics: Alcohol (2007a): Statistics on Alcohol, England. Published by the NHS Information Centre for Health and Social Care, Leeds

National Statistics (2007b): Smoking, drinking and drug use among young people in England. Edited by Fuller, E. Published by the NHS Information Centre for Health and Social Care, Leeds. (Annual Reports). Available from http://www.ic.nhs.uk/statisticsand-data-collections/health-and-lifestylesrelated-surveys/smoking-drinking-anddrug-use-among-young-people-in-england

National Statistics: Alcohol (2008a): Statistics on Alcohol, England. Published by the NHS Information Centre for Health and Social Care, Leeds

National Statistics (2008b): Smoking, drinking and drug use among young people in England. Edited by Fuller, E. Published by the NHS Information Centre for Health and Social Care, Leeds. (Annual Reports). Available from http://www.ic.nhs.uk/statisticsand-data-collections/health-and-lifestylesrelated-surveys/smoking-drinking-anddrug-use-among-young-people-in-england

National Statistics: Alcohol (2009a): Statistics on Alcohol, England. Published by the NHS Information Centre for Health and Social Care, Leeds 
National Statistics (2009b): Smoking, drinking and drug use among young people in England. Edited by Fuller, E. Published by the NHS Information Centre for Health and Social Care, Leeds. (Annual Reports). Available from http://www.ic.nhs.uk/statisticsand-data-collections/health-and-lifestylesrelated-surveys/smoking-drinking-anddrug-use-among-young-people-in-england

National Statistics (2009c): Mortality. Reference Table 6.3. Deaths: Selected Causes and Sex, England and Wales. Accessed 10 May on http://www.statistics.gov.uk/STATBASE/Product.asp?vlnk=15354

National Statistics (2009d): Mortality. Agestandardised alcohol-related death rates (with 95 per cent confidence limits) by sex and age group in the United Kingdom, 1991-2008. Data based on Office for National Statistics, General Register Office for Scotland, Northern Ireland Statistics and Research Agency

National Statistics (2010a): Statistics on Alcohol, England. Published by the NHS Information Centre for Health and Social Care

National Statistics (2010b): Smoking, drinking and drug use among young people in England. Edited by Fuller, E. Published by the NHS Information Centre for Health and Social Care, Leeds. (Annual Reports). Available from http://www.ic.nhs.uk/statisticsand-data-collections/health-and-lifestylesrelated-surveys/smoking-drinking-anddrug-use-among-young-people-in-england

National Statistics (2010c): Consumer Price Data. Alcohol Price and Retail Prices (all items) Indices derived from the publication "Focus on Consumer Price Indices", available from http://www.statistics.gov. uk/StatBase/Product.asp?vlnk=867 (last accessed 1 October 2010)

National Statistics (2010d): Mortality. Quantifying the contribution of leading causes of death to mortality decline among older people. Health Statistics Quarterly 45 Spring 2010National Statistics (2010e): Opinion Survey Drinking: adults' behaviour and knowledge in 2009 http://www. statistics.gov.uk/downloads/theme_health/ drink2009.pdf (last accessed 1 October 2010)
NDEC (2010): Alcohol Treatment Performance Reports. Available from http://www.ndtms. net/alcohol.aspx?level=England (last accessed 1 October 2010)

Newton, A. \& Sarker, J. \& Pahal, G. \& van den Bergh, E. \& Young, C. (2007): Impact of the new UK licensing law on emergency hospital attendances: a cohort study. Emergency Medicine Journal 24: 535-538

National Institute for Health and Clinical Excellence (2010): NICE public health guidance 24: Alcohol-use disorders: preventing harmful drinking. Available from http://www.nice.org.uk/nicemedia/ live/13001/48984/48984.pdf (last accessed 1 October 2010)

Nielsen (2007): Notable Decline in Scottish On Trade Alcohol Sales Since Smoking Ban. Accessed 1 May 2010 on uk.nielsen.com/ news/SmokingBan.shtml (last accessed 1 October 2010)

Ofcom/ASA (2007): Young People and Alcohol Advertising - An investigation of alcohol advertising prior to the Advertising Code changes. Available from http://www. asa.org.uk/Resource-Centre/Reports-andsurveys.aspx (last accessed 1 October 2010)

Plant, M. (2004): The alcohol harm reduction strategy for England. BMJ 328: 905 -906

Public Health Commission (2008): Briefing notes for a meeting. Downloaded $10^{\text {th }}$ April 2010 from http://www.publichealthcommission.co.uk/pdfs/PHCMeetings/P\&PoSPre-reading1.pdf (last accessed 1 October 2010)

Room, R. (2004): Disabling the public interest: Alcohol strategies and policies for England. Addiction 99: 1083-1089

SALSUS (Scottish Schools Adolescent Lifestyle and Substance Use Survey) (2009): National Report: Smoking, Drinking and Drug Use among 13 and 15 year olds in Scotland. Published by ISD Scotland, NHS Scotland and National Statistics

Smith, L.A. \& Foxcroft, D.R. (2009): Drinking in the UK: an exploration of trends. Joseph Rowntree Foundation: York, UK

UK Government (1999): Our Healthier Nation. Green Paper

UK Government (2005): Licensing Act 2003

UK Government (2010): The government 
response to the health select committee report on alcohol. http://www.official-documents.gov.uk/document/cm78/7832/7832. pdf (last accessed 1 October 2010)

Walker, A. \& Flatley, J. \& Kershaw, C. \& Moon, D. (2009): Crime in England and Wales
2008/09. Home Office Statistical Bulletin 11/09 Volume 1. Findings from the British Crime Survey and police recorded crime. http://rds.homeoffice.gov.uk/rds/pdfs09/ hosb1109vol1.pdf (last accessed 1 October 2010). 